\title{
FREQUÊNCIA DE CONSTATAÇÃO DE PERDAS POR IMPAIRMENT NAS COMPANHIAS DO SETOR SIDERÚRGICO BRASILEIRO LISTADAS NA BM\&FBOVESPA ${ }^{1}$
}

\section{FINDING FREQUENCY IMPAIRMENT LOSSES IN THE BRAZILIAN STEEL SECTOR COMPANIES LISTED ON THE BM\&FBOVESPA \\ FRECUENCIA DE CONSTATACIÓN DE PÉRDAS POR IMPAIRMENT EN LAS \\ COMPAÑIIAS DEL SECTOR SIDERÚRGICO BRASILEÑO LISTADAS EN LA BM\&FBOVESPA}

Paulo Henrique Amaral Rody, Doutorando em Ciências Contábeis pela Universidade Federal do Espírito Santo (UFES). Programa de Pós-Graduação em Ciências Contábeis PPGCON (UFES). Endereço: Av. Fernando Ferrari, 514 - Ed. ED6 - Goiabeiras - Vitória - ES - CEP 29.075-910. Telefone: +55 (27) 4009-2794. URL da Homepage: www.cienciascontabeis.ufes.br/ppgcon E-mail: paulohrody@gmail.com

Nilmara Oliveira da Luz, Especialista em Gestão Tributária e Sucessória pela FUCAPE Business School. Endereço: Av. Fernando Ferrari, n 1358. CEP: 29075-505 - Vitória, ES -

Brasil - Telefone: (27) 4009-4444. URL da Homepage: http://www.fucape.br Email: nillmara@hotmail.com

\section{RESUMO}

O objetivo deste artigo foi descrever a frequência que as empresas do setor Siderúrgico brasileiro listadas na BM\&FBovespa constataram que seus ativos imobilizados estão registrados por um valor superior ao seu valor recuperável no período de 2008 a 2014. Tratase de um estudo descritivo com abordagem qualitativa dos dados, coletados por meio de pesquisa documental de dados secundários e analisados por meio da técnica análise de conteúdo. As análises foram feitas dos seguintes relatórios contábeis: Balanço Patrimonial (BP), Demonstração do Resultado do Exercício (DRE), Notas Explicativas (NE's) e Relatórios da Administração (RA's) dos exercícios sociais compreendidos entre 2008 a 2014 de todas as empresas do setor Siderúrgico brasileiro listadas na BM\&FBovespa. Os principais resultados encontrados foram: 60\% dessas empresas após a aplicação do teste de recuperabilidade nos ativos imobilizados, constataram que seus ativos imobilizados não estavam registrados por um valor superior ao valor recuperável, por isso não registram perda por impairment de ativo imobilizado; $40 \%$ das empresas registraram perda por impairment, sendo $20 \%$ com o registro da perda em 1 ano, e $20 \%$ registraram a perda em 2 anos; e em 91,43\% dos anos investigados, as empresas não constataram que seus ativos imobilizados estavam registrados por um valor superior ao valor recuperável.

Palavras-chave: Impairment Test. Ativo Imobilizado.

\section{ABSTRACT}

The aim of this paper was to describe the frequency that companies in the Brazilian Steel sector listed on the BM \& FBovespa found that its fixed assets are recorded at a value higher than its recoverable amount from 2008 to 2014. It is a study descriptive with qualitative

1 Artigo submetido em 10/06/2018, revisado em 10/08/2018, aceito em 26/08/2018 e divulgado em 28/10/2019 pelo Editor Alexandre Rabêlo Neto, após double blind review.

GєCont, v.6, n. 1, Floriano-PI, Jan-Jun. 2019. 
approach, collected through desk research of secondary data and analyzed using content analysis technique. Analyses were made of the following financial reports: Balance Sheet, the Income Statement, Notes and Management Reports for fiscal years ranging from 2008 to 2014 of all companies in the sector Brazilian steel listed on BM \& FBovespa. The main results were: $60 \%$ of these firms after application of the impairment test on the fixed assets, found that its fixed assets were not recorded by a value greater than the recoverable value, so do not record impairment loss of fixed assets; $40 \%$ of companies recorded impairment, $20 \%$ with the loss of record at 1 year, and 20\% reported a loss in 2 years; and $91.43 \%$ of the investigated years, companies have not found that its fixed assets were recorded at an amount higher than the recoverable amount.

Keywords: Impairment Test. Fixed Assets.

\section{RESUMEN}

El objetivo de este artículo fue describir la frecuencia que las empresas del sector Siderúrgico brasileño listadas en la BM \& FBovespa constataron que sus activos inmovilizados están registrados por un valor superior a su valor recuperable en el período de 2008 a 2014. Se trata de un estudio descriptivo con abordaje cualitativo de los datos, recogidos por medio de investigación documental de datos secundarios y analizados por medio de la técnica análisis de contenido. Los análisis se realizaron de los siguientes informes contables: Balance Balance (BP), Demostración del Resultado del Ejercicio (DRE), Notas Explicativas (NE's) e Informes de la Administración (RA) de los ejercicios sociales comprendidos entre 2008 a 2014 de todas las empresas del sector Siderúrgico brasileño listadas en la BM \& FBovespa. Los principales resultados encontrados fueron: $60 \%$ de esas empresas después de la aplicación del test de recuperabilidad en los activos inmovilizados, constataron que sus activos inmovilizados no estaban registrados por un valor superior al valor recuperable, por lo que no registra pérdida por deterioro de activo inmovilizado; El $40 \%$ de las empresas registraron pérdida por deterioro, siendo el $20 \%$ con el registro de la pérdida en 1 año, y el 20\% registró la pérdida en 2 años; y en el 91,43\% de los años investigados, las empresas no constataron que sus activos inmovilizados estaban registrados por un valor superior al valor recuperable.

Palabras clave: Impairment Test. Activo Inmovilizado.

GєCont, v.6, n. 1, Floriano-PI, Jan-Jun. 2019. 


\section{INTRODUÇÃO}

Diante da instabilidade econômica e certos fenômenos que ocorrem no mercado, onde as variações dos preços são constantes, mesmo utilizando o valor justo para registro de ativos e passivos, eles podem ficar deslocados da realidade. Valor justo é o valor pelo qual um ativo pode ser negociado, ou um passivo liquidado, entre partes interessadas, conhecedoras do negócio e independentes entre si, com a ausência de fatores que pressionem para a liquidação da transação ou que caracterizem uma transação compulsória (COELHO, 2010). Dentro do contexto do valor justo insere-se o teste de recuperabilidade de ativos que tem como objetivo aumentar o grau de fidedignidade das informações dos ativos a que se referem. A relação entre Valor Justo e Teste de Recuperabilidade foi objeto de estudo na pesquisa de Raupp e Beuren (2009).

Diante desse cenário, a entrada em vigor da Lei $n^{\circ}$. 11.638/2007, no dia $1^{\circ}$ de janeiro de 2008, deu início ao procedimento de adequação do Brasil às normas internacionais de contabilidade. Em meio às muitas alterações causadas pela atual legislação, o Teste de Recuperabilidade de Ativos conhecido também como Impairment Test, pode ser analisado como um dos pontos de maior impacto nos demonstrativos financeiros das entidades. Vale ressaltar que a referida Lei foi alterada pela Lei $\mathrm{n}^{\circ}$. 11.941/2009, e esta foi recentemente alterada pela Lei $\mathrm{n}^{\circ}$. 12.973/2014. Pesquisa realizada por Santos (2012) sobre o impacto do processo de convergência das normas contábeis brasileiras ao padrão International Financial Reporting Standard (IFRS) nas demonstrações contábeis, verificou que a exclusão dos custos de transação e prêmios na emissão de títulos do resultado triplicou o lucro das empresas e o impairment de ativos gerou queda média de $260 \%$ no lucro das empresas que o registraram em 2008. Pesquisa realizada por Ahmed e Alam (2012) sobre os efeitos da adoção do IFRS nas demonstrações contábeis, constatou que não ocorreram alterações significativas na posição financeira global dos relatórios contábeis das empresas analisadas. Nessa mesma linha Trewavas, Redmayne e Laswad (2012) destacam que a adesão ao IFRS torna possível apresentar de forma mais adequada as demonstrações contábeis de uma entidade.

A expressão Impairment Test vem do inglês e é usada para explicar a redução de valor recuperável de um bem do ativo. Ele é aplicado por uma empresa para verificar se seus ativos de longo prazo ou de natureza permanente não sejam registrados contabilmente por um valor superior aquele a que possam ser recuperados por uso ou por venda (CPC 01, 2010). O Impairment Test é o instrumento utilizado para adequar o ativo a sua real capacidade de retorno econômico. Este é aplicado em ativos fixos (ativo imobilizado), ativos de vida útil indefinida (goodwill), ativos disponíveis para venda, investimentos em operações descontinuadas (SILVA et al., 2006).

O conceito de Impairment Test já vem sendo adotado pelas empresas brasileiras há décadas para alguns itens do ativo como destaca Szuster (2008). No Brasil o pronunciamento técnico CPC 01 (2010) emitido pelo Comitê de Pronunciamentos Contábeis define a metodologia a ser aplicada para o teste de recuperabilidade de ativos. Diversas empresas apresentam as informações acerca do teste de recuperabilidade de ativos nas demonstrações contábeis, apenas de forma descritiva quanto às orientações emitidas pelo CPC 01 (2010), a ausência do caráter explicativo nos relatórios contábeis pode comprometer a transparência e fidedignidade das informações evidenciadas (REIS et al., 2013).

Para Amaro et al. (2015) o caráter subjetivo presente no cálculo das perdas por impairment pode ser alvo de manipulação pelos gestores para fins de gerenciamento de

GєCont, v.6, n. 1, Floriano-PI, Jan-Jun. 2019. 
resultados a favor destes; para promover melhorias nas informações divulgadas, os organismos legais poderiam delimitar de forma mais específica e objetiva as métricas no cálculo do impairment test. Outro problema, é a não aplicação do teste de recuperabilidade de ativos por determinadas empresas, mesmo sendo obrigadas pela Legislação Contábil (NASCIMENTO et al., 2013). Nesse mesmo contexto, inclusive entre as empresas que aplicam o impairment test, uma quantidade substancial entre estas cumprem parcialmente as determinações emanadas pelo CPC 01 (2010), o que pode comprometer a qualidade das informações contábeis divulgadas (ONO; RODRIGUES; NIYAMA, 2010; TAVARES et al., 2010; SOUZA; BORBA; ZANDONAI, 2011). Nessa mesma linha, pesquisa realizada por Mazzioni et al. (2014) sobre impairment test das empresas listadas na Bovespa, verificou que $34 \%$ das empresas da amostra não informaram a forma utilizada para cálculo do valor recuperável.

Diversos artigos foram produzidos abordando o tema impairment test, como as pesquisas de (ROMANO, 2008; CHEN; WANG; ZHAO, 2008; CARLIN; FINCH, 2011; MARQUES, 2013; BOWEN; KHAN, 2014; ABUADDOUS; HANEFAH; LAILI, 2014; DAMASCENO; FUNCHAL, 2015) pesquisas que focaram na relação entre impairment test e gerenciamento de resultados; reversão da perda por impairment; relação entre impairment test e valor justo; evidenciação e aderência na aplicação do impairment test com o CPC 01 (2010), entre outras abordagens. Entretanto, conforme pesquisa bibliográfica realizada em mais de 30 periódicos na área de contabilidade e administração, nenhum dos artigos encontrados abordou o tema impairment test com o objetivo de investigar o nível de frequência de ocorrência de registro de perda por impairment nas demonstrações contábeis. O que gera uma lacuna no meio científico, proporcionando uma linha de pesquisa ainda inexplorada a ser preenchida.

Dentro desse cenário, como o reconhecimento da perda por desvalorização do ativo só ocorre quando este possuir valor contábil superior a seu valor recuperável, não será sempre que uma empresa ao aplicar o teste de recuperabilidade em seus ativos, irá reconhecer essa perda, como constataram as pesquisas de Bezerra, Gallon e Luca (2014) e Bianchi et al. (2015), que das empresas das amostras, uma pequena parcela delas reconheceram a perda por desvalorização do ativo. Assim, o problema de pesquisa proposto focalizou a seguinte questão: Qual é a frequência que as empresas do setor Siderúrgico brasileiro listadas na BM\&FBovespa constataram que seus ativos imobilizados estão registrados por um valor superior ao seu valor recuperável no período de 2008 a $2014 ?$

Desse modo este artigo teve como objetivo geral: descrever a frequência que as empresas do setor Siderúrgico brasileiro listadas na BM\&FBovespa constataram que seus ativos imobilizados estão registrados por um valor superior ao seu valor recuperável no período de 2008 a 2014. E como objetivos específicos: 1) identificar a frequência com que cada uma dessas empresas constataram que seus ativos imobilizados estão registrados por um valor superior ao seu valor recuperável; 2) verificar a frequência de ocorrência de perdas por impairment de ativo imobilizado proporcional a quantidade de empresas e a quantidade de registros de perdas por ano.

Uma vez que ao aplicar o teste de recuperabilidade em seus ativos as empresas, somente registrarão a perda por desvalorização de ativo, ao constatarem que o valor de seus ativos possui valor contábil superior ao recuperável; torna-se relevante investigar o nível de frequência de ocorrência de perda por impairment de ativo registrados por determinada quantidade de empresas, dada certa amplitude temporal das demonstrações contábeis divulgadas pelas mesmas. Com o intuito de na prática, descrever o panorama sobre a

GєCont, v.6, n. 1, Floriano-PI, Jan-Jun. 2019. 
frequência que as empresas constataram que seus ativos estão registrados por um valor superior ao recuperável, destacando a proporção de ocorrência e não ocorrência de perda por desvalorização de ativo pela aplicação do impairment test. Possibilitando dessa forma, fazer inferências sobre o nível de ocorrência de perdas por desvalorização de ativos registradas pelas empresas do setor Siderúrgico brasileiro de 2008 a 2014.

As próximas partes da pesquisa foram organizadas desta forma: (2) Referencial Teórico: foram abordados os assuntos pertinentes relacionados ao tema deste artigo, utilizando como referências autores de livros e artigos científicos, bem como a legislação e normas contábeis vigentes; (3) Metodologia: foi evidenciado como os dados da pesquisa foram coletados e analisados, bem como os demais aspectos relevantes relacionados à metodologia da pesquisa; (4) Descrição e Análise dos Resultados: pesquisa documental e análise de conteúdo das demonstrações contábeis das empresas do setor Siderúrgico listadas na BM\&FBovespa de 2008 a 2014; (5) Conclusão: avaliaram-se as respostas obtidas através da coleta e análise dos dados confrontando-as com o problema de pesquisa e com os objetivos da pesquisa; apresentaram-se as contribuições para a ampliação do fenômeno estudado; comentam-se as limitações da pesquisa e recomendações para futuras pesquisas.

\section{REFERENCIAL TEÓRICO}

\subsection{TESTE DE RECUPERABILIDADE DE ATIVOS}

Em 2008 o Brasil deu início ao processo de convergência às normas internacionais de contabilidade, com a publicação da Lei $\mathrm{n}^{\circ}$. 11.638/2007. Uma das regras fundamentais da contabilidade com a convergência às normas internacionais é que o ativo não pode ficar registrado contabilmente por um valor acima do valor recuperável. Para ser verificar se os valores de registro de seus ativos na contabilidade continuam retratando a realidade deve ser realizada o impairment test, que também é conhecido como teste de recuperabilidade dos ativos.

No Brasil, o Comitê de Pronunciamentos Contábeis (CPC), emitiu o pronunciamento CPC 01 (2010), definindo que a entidade deve aplicar o teste de recuperabilidade de ativos para assegurar que seus ativos estejam registrados contabilmente por valor que não exceda seus valores de recuperação. Um ativo está registrado contabilmente por valor que excede seu valor de recuperação se o seu valor contábil exceder o montante a ser recuperado pelo uso ou pela venda do ativo. Se esse for o caso, o ativo é caracterizado como sujeito ao reconhecimento de perdas, e esse mesmo $\mathrm{CPC}$ requer que a entidade reconheça um ajuste para perdas por desvalorização. Tal CPC também especifica quando a entidade deve reverter um ajuste para perdas por desvalorização e estabelece as divulgações requeridas.

Considerando que um ativo deve ter a capacidade de gerar benefícios presentes ou futuros para a entidade que o controla, é importante calcular o valor de retorno deste bem ou direito. Conforme a Lei $\mathrm{n}^{\mathrm{o}}$. 11.638/07 é necessário efetuar determinados processos para validar o teste de recuperabilidade dos ativos. O teste de recuperabilidade de ativos é um termo inglês e em sentido literal sua tradução para o português significa redução de capital ou descapitalização. O Impairment Test tem por objetivo assegurar que o valor contábil líquido de um ativo ou de um grupo de ativos de longo prazo não seja superior ao seu valor recuperável, sendo este último o maior entre o valor líquido de venda e o valor em uso (CPC 01, 2010). O impairment test é pautado em critérios conservadores, uma vez que somente produz impacto nas demonstrações contábeis, quando há ocorrência de perda (WATTS, 2003).

GєCont, v.6, n. 1, Floriano-PI, Jan-Jun. 2019. 
De acordo com o CPC 01 (2010), a perda por impairment dos ativos descontinuados ou disponíveis para venda, deve ser reconhecida pelo seu valor de mercado ou pelo valor de ativos similares, ou seja, pelo valor líquido de venda. Além disso, ampliou a apuração do impairment também para os ativos em uso. Sendo assim, deve-se registrar a perda quando o valor contábil do ativo for superior ao seu valor em uso indicado pelo valor presente de fluxos de caixa futuros estimados. O uso do impairment test para o goodwill no lugar de amortização, pode produzir efeito favorável no resultado financeiro de determinadas organizações (BAKER; WEARING, 2001; PACHARN; ZHANG, 2006).

Ajuste a valor presente consiste em adequar o valor de um ativo ou de um passivo em função de seu tempo de realização ou exigibilidade, levando em conta uma taxa de desconto adequado ao tipo de ativo e passivo. Portanto, Significa trazer o valor futuro de um ativo ou passivo para o valor equivalente a data do balanço (BORINELLI, 2010). Quando ocorre uma perda por impairment, a entidade deve ajustar o valor contábil ao valor justo do ativo, o qual é obtido através do valor do mercado do ativo similar. Contudo, se não existir um mercado regular para o ativo, onde possa ser aferido o seu valor, neste caso o valor justo será obtido pela expectativa de valor presente líquido do fluxo de caixa futuro (SANTOS et al., 2007).

Iudícibus et al. (2010) menciona que se os ativos estiverem avaliados por valor superior ao valor recuperável por meio do uso ou da venda, a entidade devera reduzir esses ativos ao seu valor recuperável, reconhecendo o resultado à perda referente a essa desvalorização. Carvalho, Lemes e Costa (2009) definem o valor recuperável como o maior valor entre o preço líquido de venda do ativo e o seu valor em uso. $\mathrm{O}$ teste de recuperabilidade se tornou obrigatório a partir de 31/12/2008 com a Lei $\mathrm{n}^{\circ}$. 11.638/2007 e deve se aplicado no mínimo a cada fim de exercício social, ele pode ser executado em qualquer instante num intervalo de um ano, desde que seja executado todo o ano no mesmo período.

Caso houver alguma indicação de desvalorização a entidade deve estimar o valor recuperável do ativo por meio de um impairment test. O resultado do teste será contabilizado somente se o valor recuperável for inferior ao valor que está contabilizado. Caso o valor recuperável seja superior ou igual ao que está contabilizado, o ativo permanece registrado pelo seu valor original. O objetivo do Pronunciamento Técnico CPC 01 (2010) é assegurar através desses procedimentos que os ativos não estejam registrados contabilmente por um valor superior aquele passível de ser recuperado no tempo de uso nas operações da entidade ou em sua eventual venda.

Com a alteração da Lei $\mathrm{n}^{\circ}$. 6.404/76 a contabilidade que registrava seus bens e direitos pelo custo histórico passa a registrar os mesmos com Base nos benefícios econômicos futuros que poderão gerar para a empresa. Conforme Mazzioni et al. (2014) o grupo de ativos que mais recebe o teste de recuperabilidade é o imobilizado, e a base mais utilizada para cálculo do valor recuperável é o valor em uso. Já a pesquisa realizada por Uliano, Gonçalves e Doná (2014) revelou que as informações mais divulgadas sobre a aplicação do impairment pelas empresas analisadas foram o valor da perda e a natureza do ativo.

\subsection{VALOR CONTÁBIL E VALOR RECUPERÁVEL}

O valor contábil de uma empresa se refere ao valor dos recursos próprios que aparecem no seu balanço. Já o valor recuperável é o maior valor entre o valor líquido de venda de um ativo e seu valor em uso. Para identificar o valor recuperável a entidade depende do cálculo de dois outros montantes: valor em uso e valor justo líquido dos custos de venda. $\mathrm{O}$ 
valor recuperável, do ativo ou da unidade geradora de caixa, é o maior entre os dois (LEMES; CARVALHO, 2010).

O valor em uso de um ativo é o valor presente de fluxos de caixa futuros esperados que devam incidir de um ativo ou de unidade geradora de caixa. Já o valor justo é o valor pelo qual um ativo pode ser negociado entre partes interessadas.

Com as alterações da Lei $n^{\circ}$. 6.404/76 o ativo não pode estar registrado por um valor maior o que o valor recuperável, e devido a isso, as empresas devem testar seus ativos anualmente de acordo o CPC 01 (2010) com a aplicação do impairment test.

\subsection{MENSURAÇÃO DO VALOR RECUPERÁVEL}

O CPC 01 (2010) determina que a entidade deve avaliar, na data de cada balanço patrimonial, se existe ou não qualquer evidência objetiva de que um ativo ou grupo de ativos esteja sujeito a perda no valor recuperável. Se tal evidência existir, a entidade deve aplicar o Impairment Test.

Para o reconhecimento de um ativo desvalorizado, o CPC 01, assim como a IAS 36, considera fatores internos e externos. Dos fatores externos, é citada a redução do valor de mercado de um ativo; a significante mudança de ambiente tecnológico e mercadológico e pelo relevante aumento das taxas de juros o que leva à redução no retorno sobre o investimento e ainda, quando o valor contábil do patrimônio supera o valor de suas ações no mercado. Dos fatores internos evidência a obsolescência ou de danos físicos em um ativo; planejamento de descontinuação ou reestruturação de um ativo e ainda desempenho econômico de um ativo menor que a expectativa indicada em relatórios internos.

Segundo o CPC 01 (2010) para aplicar o impairment test é indispensável que a entidade execute as seguintes etapas:

- Determinação do valor contábil líquido do bem pelo custo histórico diminuído da depreciação/amortização ou exaustão acumulada e de provisões para perdas;

- Determinação do valor recuperável do bem que pode ser feito pelo valor líquido de venda, ou valor justo, diminuído os custos da transação; ou pelo valor líquido de uso que é determinado pelo valor presente de fluxo de caixa que será gerado pelo uso do bem nas atividades ou na produção;

- Fazer comparações entre o valor contábil e o valor recuperável. Quando o valor de realização do ativo apresentar-se maior que o seu valor contábil, não será necessário nenhum registro. No entanto, se o valor realizável do ativo mostrar-se menor que o valor contábil a empresa deverá efetuar o ajuste.

No caso da mensuração do valor recuperável nem sempre é necessário definir o valor justo líquido de despesas de venda de um ativo e seu valor em uso. Se qualquer um desses montantes excederem o valor contábil do ativo, ele não tem desvalorização e, deste modo, não é necessário estimar o outro valor.

\subsection{PERDA POR DESVALORIZAÇÃO}

Conforme o CPC 01 (2010) a entidade deve reconhecer uma perda por desvalorização de um ativo imobilizado no resultado do período apenas se o valor contábil desse imobilizado for superior ao seu valor recuperável. Nessa situação a entidade deve reduzir do valor contábil

GєCont, v.6, n. 1, Floriano-PI, Jan-Jun. 2019. 
do ativo imobilizado o seu valor recuperável. A perda por desvalorização a ser reconhecida no resultado do período é mensurada com base no montante em que o valor contábil do imobilizado supera o seu valor recuperável.

Para os ativos reavaliados o valor da perda deve ser baixado da reserva de reavaliação ao invés de ser lançado no resultado.

De acordo com Lemes e Carvalho (2010) ao contabilizar a perda por impairment, a redução do valor contábil dos ativos que compõe a unidade geradora de caixa deverá ser reconhecida na seguinte ordem: primeiro reduz-se o valor do goodwill da unidade; e remanescendo perda a ser alocada, reduz-se o valor contábil dos ativos, proporcionalmente ao seu valor relativo na unidade.

Assim, ao alocar uma perda por impairment, segundo Lemes e Carvalho (2010), o valor contábil do ativo será reduzido até o maior valor entre o valor justo líquido e o valor em uso. Caso esse dois valores sejam negativos, o valor contábil será reduzido somente até zero.

\subsection{EVIDENCIAÇÃO/DISCLOSURE DAS INFORMAÇÕES DO IMPAIRMENT TEST}

A Norma brasileira no tocante a evidenciação da perda no valor recuperável de ativos é divulgada pelo CPC 01 (2010). A evidenciação das perdas é essencial para a transparência dos valores informados.

O CPC 01 (2010) destaca a importância da evidenciação do teste realizado pelas empresas mencionando que a entidade é encorajada a divulgar as premissas utilizadas para determinar o valor recuperável de ativos (unidades geradoras de caixa) periodicamente. Entretanto, o item 134 desse pronunciamento exige que a entidade divulgue informações acerca das estimativas utilizadas para mensurar o valor recuperável de uma unidade geradora de caixa quando o ágio por expectativa de rentabilidade futura (goodwill) ou o ativo intangível de vida útil indefinida estiver incluído no valor contábil da unidade.

De acordo com Lemes e Carvalho (2010) para cada classe de Ativo, a entidade deverá divulgar: o valor das perdas por impairment e das reversões reconhecidas na demonstração de resultado e as linhas da demonstração de resultado abrangente nas quais a perda e a reversão foram incluídas; b) o valor das perdas por impairment e das reversões de ativos reavaliados reconhecidos em outros resultados abrangentes. Pesquisa realizada por Machado et al. (2013) sobre evidenciação de valor recuperável de ativos em empresas do mercado acionário brasileiro, constatou que as empresas que apresentaram perdas por impairment alcançaram níveis superiores de divulgação de informações sobre a decisão de reconhecer perdas e sobre o nível de detalhamento quanto a mensuração do valor recuperável.

As empresas que apresentam informações por segmentos, para cada segmento, devem divulgar o valor das perdas por impairment e das reversões reconhecidas na demonstração de resultado e em outros resultados abrangentes. Já foi constatado por diversas pesquisas, como a realizada por Devalle e Rizzato (2012), que embora seja obrigatório a divulgação adequada das informações contábeis, percebe-se que a obrigatoriedade de divulgação não significa necessariamente que todas as informações são divulgadas pelas empresas, o que aumenta o nível de assimetria informacional entre os usuários das informações contábeis. Nessa mesma linha Ono, Rodrigues e Niyama (2010) e Machado, Machado e Floresta (2014) verificaram elevada falta de transparência e inadequação nas informações divulgadas nas demonstrações contábeis das empresas das amostras investigadas. Nessa mesma linha Uliano, Gonçalves e 
Doná (2014) verificaram que das empresas analisadas nenhuma delas atenderam completamente as determinações do CPC 01 (2010).

Entre as principais informações divulgadas pelas empresas que aplicam o impairment test figuram: o valor da perda e a maneira de mensuração do valor recuperável; e a principal informação não evidenciada por determinadas empresas é a taxa de desconto utilizada nas projeções de fluxo de caixa descontado (SOUZA; BORBA; ZANDONAI, 2011).

\subsection{REVERSÃO DO IMPAIRMENT TEST}

O CPC 01 (2010) nos itens 109 a 125 mencionam sobre a reversão do teste de recuperabilidade. De acordo com ele quando a perda por desvalorização reconhecida em períodos anteriores para um ativo imobilizado não existir mais ou ter diminuído, deve ser revertido, exceto no caso do ágio por expectativa de rentabilidade futura (goodwill).

A reversão de perda por desvalorização de um ativo, exceto o ágio por expectativa de rentabilidade futura (goodwill), deve ser reconhecida imediatamente no resultado do período, a menos que o ativo esteja registrado por valor reavaliado de acordo com outro Pronunciamento (CPC 01, 2010).

A reversão da perda em questão deve ser reconhecida no resultado do período. Esta reversão pode ser aplicada no ativo individual quanto na unidade geradora de caixa.

\section{METODOLOGIA}

Os dados desta pesquisa foram tratados de forma qualitativa. Para Martins e Theóphilo (2007) a pesquisa qualitativa é o estudo aprofundado de determinado fenômeno que visa compreender, interpretar e analisar dados que não são passíveis de serem expressos por dados numéricos. Esta pesquisa enquadra-se como descritiva, que tem como principal objetivo descrever as características de determinado fenômeno, o que implica na análise e no registro do objeto estudado (MARION; DIAS; TRALDI, 2002). Os dados foram coletados por meio de pesquisa documental de dados secundários, que é realizada em documentos conservados por órgãos públicos e privados de qualquer natureza, estes que receberam algum tipo de tratamento prévio (VERGARA, 2005).

Através da análise de conteúdo, todas as informações coletadas foram analisadas e interpretadas à luz do referencial teórico e dos objetivos da pesquisa. De acordo com Martins e Theóphilo (2007) a análise de conteúdo busca a essência de um texto nos detalhes das informações, o interesse não se restringe à descrição dos conteúdos, deseja-se inferir sobre o todo, buscando compreender os efeitos e consequências dessas informações. Por fim, todos os dados após serem coletados, preparados e organizados foram confrontados com o problema de pesquisa e os objetivos da pesquisa, conduzindo dessa forma, a análise e interpretação dos dados obtidos para a conclusão da pesquisa.

As análises deste artigo foram feitas dos seguintes relatórios contábeis: Balanço Patrimonial (BP), Demonstração do Resultado do Exercício (DRE), Notas Explicativas (NE's) e Relatórios da Administração (RA's) dos exercícios sociais compreendidos entre 2008 a 2014 das empresas do setor Siderúrgico brasileiro listadas na BM\&FBovespa.

Tabela 1: Representatividade do Ativo Imobilizado em relação ao Ativo Total 


\begin{tabular}{c|c}
\hline Cia Ferro Ligas da Bahia - FERBASA & $38,64 \%$ \\
\hline Cia Siderúrgica Nacional & $31,39 \%$ \\
\hline Gerdau S.A. & $35,1 \%$ \\
\hline Metalúrgica Gerdau S.A. & $35 \%$ \\
\hline Usinas Sid de Minas Gerais S.A.-USIMINAS & $50,96 \%$ \\
\hline
\end{tabular}

Fonte: Elaborado pelos autores.

A escolha deste setor que compõe a amostra deste artigo se deve a significativa representatividade dos ativos imobilizados das mesmas, entre $30 \%$ e $50,96 \%$ dos ativos totais. $\mathrm{O}$ que se presume ser uma razoável base de dados para o fenômeno estudado por esta pesquisa.

Esse artigo possui como limitação, ter utilizado uma amostra pequena, de apenas 5 empresas, a escolha de tal amostra foi motivada, para viabilizar a conclusão deste artigo numa pesquisa preparatória para uma pesquisa seguinte a ser realizada posteriormente, na qual será utilizada uma amostra maior. Entretanto, se por um lado ter utilizado uma amostra pequena, trouce certas limitações a esta pesquisa, por outro lado, além de analisar as empresas da amostra de forma geral, foi possível realizar análise individual de cada empresa, permitindo fazer inferências individuais e gerais sobre a frequência de ocorrência de perda por impairment no imobilizado das empresas que compõem o setor Siderúrgico brasileiro listadas na BM\&FBovespa de 2008 a 2014.

\section{DESCRIÇÃO E ANÁLISE DOS RESULTADOS}

Este tópico analisou os seguintes relatórios contábeis: Balanço Patrimonial (BP), Demonstração do Resultado do Exercício (DRE), Notas Explicativas (NE's) e Relatórios da Administração (RA's) de todas as empresas que compõem o setor Siderúrgico brasileiro listadas na BM\&FBovespa de 2008 a 2014, assim foi evidenciado o panorama sobre a frequência de ocorrência de perda por impairment nos respectivos ativos imobilizados dessas empresas, como discriminado a seguir ao longo deste tópico.

Quadro 1: Ocorrência de Perda por Desvalorização de Ativo Imobilizado na Cia Ferro Ligas da Bahia FERBASA

\begin{tabular}{c|c|c}
\multirow{2}{*}{ ANO } & REGISTRO DE PERDA POR DESVALORIZAÇ̃̃O DE ATIVO \\
\cline { 2 - 3 } & SIM & NÃO \\
\hline 2008 & & $X$ \\
\hline 2009 & & $X$ \\
\hline 2010 & & $X$ \\
\hline 2011 & & $X$ \\
\hline 2012 & & $X$ \\
\hline 2013 & & $X$ \\
\hline 2014 & & $X$ \\
\hline
\end{tabular}

Fonte: Elaborado pelos autores.

GєCont, v.6, n. 1, Floriano-PI, Jan-Jun. 2019. 
Conforme dados do quadro 1 anterior, pela análise das NE's foi observado que a empresa aplicou o impairment test no ativo imobilizado em todos os anos e constatou que o mesmo não possuía valor contábil maior que o valor recuperável nos anos de 2008 a 2014, por esse motivo não foi registrado a perda por desvalorização de ativo. Com base na análise das NE's da empresa notou-se que embora a empresa tenha aplicado o teste de recuperabilidade no ativo imobilizado de 2008 a 2014, o termo impairment passou a ser empregado somente em 2010, e o mesmo se repetiu nos anos seguintes até 2014; nos anos anteriores (2008-2009), as NE's não fizeram menção ao termo impairment, apenas citava-se que a empresa verificava habitualmente se o valor contábil do ativo imobilizado possuía valor superior ao valor recuperável.

Quadro 2: Ocorrência de Perda por Desvalorização de Ativo Imobilizado na Cia Siderúrgica Nacional

\begin{tabular}{c|c|c}
\hline \multirow{2}{*}{ ANO } & REGISTRO DE PERDA POR DESVALORIZAÇÃO DE ATIVO \\
\cline { 2 - 3 } & SIM & NÃO \\
\hline 2008 & & $\mathrm{X}$ \\
\hline 2009 & & $\mathrm{X}$ \\
\hline 2010 & & $\mathrm{X}$ \\
\hline 2011 & & $\mathrm{X}$ \\
\hline 2012 & & $\mathrm{X}$ \\
\hline 2013 & & $\mathrm{X}$ \\
\hline
\end{tabular}

Fonte: Elaborado pelos autores.

Baseado nos dados do quadro 2 anterior, pela análise das NE's verificou-se que a empresa aplicou o impairment test no ativo imobilizado em todos os anos e constatou que o mesmo não possuía valor contábil superior ao valor recuperável nos anos de 2008 a 2014. Pela análise das NE's contatou-se que as mesmas utilizaram o termo impairment em todos os anos.

Quadro 3: Ocorrência de Perda por Desvalorização de Ativo Imobilizado na Cia Gerdau S.A

\begin{tabular}{c|c|c}
\hline \multirow{2}{*}{ ANO } & REGISTRO DE PERDA POR DESVALORIZAÇÃO DE ATIVO \\
\cline { 2 - 3 } & SIM & NÃO \\
\hline 2008 & & $\mathrm{X}$ \\
\hline 2009 & $\mathrm{X}$ & $\mathrm{X}$ \\
\hline 2010 & & $\mathrm{X}$ \\
\hline 2011 & & $\mathrm{X}$ \\
\hline 2012 & $\mathrm{X}$ & $\mathrm{X}$ \\
\hline 2013 & & \\
\hline 2014 & & \\
\hline
\end{tabular}

Fonte: Elaborado pelos autores.

Por meio dos dados do quadro 3 anterior, pela análise das NE's notou-se que a empresa aplicou o impairment test no ativo imobilizado em todos os anos e constatou que o mesmo não possuía valor contábil superior ao valor recuperável nos anos de 2010 a 2013 e

GєCont, v.6, n. 1, Floriano-PI, Jan-Jun. 2019. 
2008; enquanto nos anos de 2009 e 2014 a empresa registrou a perda por desvalorização de ativo na Demonstração do Resultado, após constatar por meio da aplicação do impairment test que o valor contábil do ativo possuía valor superior ao seu valor recuperável. Conforme análise das NE's verificou-se que as mesmas utilizaram o termo impairment em todos os anos.

Quadro 4: Ocorrência de Perda por Desvalorização de Ativo Imobilizado na Cia Metalúrgica Gerdau S.A

\begin{tabular}{c|c|c}
\multirow{2}{*}{ ANO } & \multicolumn{2}{|c}{ REGISTRO DE PERDA POR DESVALORIZAÇÃO DE ATIVO } \\
\cline { 2 - 3 } & SIM & NÃO \\
\hline 2008 & & $\mathrm{X}$ \\
\hline 2009 & $\mathrm{X}$ & $\mathrm{X}$ \\
\hline 2010 & & $\mathrm{X}$ \\
\hline 2011 & & $\mathrm{X}$ \\
\hline 2012 & & $\mathrm{X}$ \\
\hline 2013 & & $\mathrm{X}$ \\
\hline 2014 & & \\
\hline
\end{tabular}

Fonte: Elaborado pelos autores.

Os do quadro 4 anterior, pautado na análise das NE's indicam que a empresa aplicou o impairment test no ativo imobilizado em todos os anos e constatou que o mesmo não possuía valor contábil superior ao valor recuperável nos anos de 2010 a 2014 e 2008; já no ano de 2009 somente, a empresa registrou a perda por desvalorização de ativo na Demonstração do Resultado. Pela análise das NE's notou-se que as mesmas empregaram o termo impairment em todos os anos.

Quadro 5: Ocorrência de Perda por Desvalorização de Ativo Imobilizado na Cia Usinas Sid de Minas Gerais S.A.-USIMINAS

\begin{tabular}{c|c|c}
\multirow{2}{*}{ ANO } & \multicolumn{2}{|c}{ REGISTRO DE PERDA POR DESVALORIZAÇÃO DE ATIVO } \\
\cline { 2 - 3 } & SIM & NÃO \\
\hline 2008 & & $\mathrm{X}$ \\
\hline 2009 & & $\mathrm{X}$ \\
\hline 2010 & & $\mathrm{X}$ \\
\hline 2011 & & $\mathrm{X}$ \\
\hline 2012 & & $\mathrm{X}$ \\
\hline 2013 & & \\
\hline
\end{tabular}

Fonte: Elaborado pelos autores.

Tendo por base os dados do quadro 5 anterior, pela análise das NE's foi observado que a empresa aplicou o impairment test no ativo imobilizado em todos os anos e constatou que o mesmo não possuía valor contábil maior que o valor recuperável nos anos de 2008 a 2014, por esse motivo não foi registrado a perda por desvalorização de ativo. Também foi verificado que as NE's empregaram o termo impairment em todos os anos.

GєCont, v.6, n. 1, Floriano-PI, Jan-Jun. 2019. 
Conforme informado nas NE's todas as empresas da amostra mencionaram realizar o teste de recuperabilidade de seus ativos anualmente em obediência as determinações do CPC 01 (2010). Entre as empresas da amostra algumas registraram perdas por impairment de Ágio, estas não foram consideradas por este estudo assim como outras espécies de perda por impairment, uma vez que este artigo focou nas perdas por impairment exclusivamente do Ativo Imobilizado.

Após analisar as demonstrações contábeis de 7 exercícios sociais (2008-2014) das 5 empresas que compõem o setor Siderúrgico brasileiro listadas na BM\&FBovespa, gerando um total de 35 possibilidades de ocorrência de registro de perda por desvalorização de ativo imobilizado, conforme dados dos quadros 01-05 anteriores, verificou-se somente 3 ocorrências de registro de perda por desvalorização de ativo imobilizado, por apenas 2 empresas que constataram que seus ativos imobilizados possuíam valores contábeis superiores aos seus valores recuperáveis; enquanto foram evidenciadas 32 não ocorrências de registro de perda por desvalorização de ativo imobilizado, e das 5 empresas da amostra 3 delas não registraram tal perda em ano nenhum.

Tabela 2: Proporção de Registro de Perda por Impairment do Ativo Imobilizado em relação ao Total de Empresas

\begin{tabular}{c|c|c}
\hline NÚMERO DE EMPRESAS & REGISTROS DE PERDAS & PROPORÇÃO DE EMPRESAS \\
\hline 3 & 0 & $60 \%$ \\
\hline 1 & 1 & $20 \%$ \\
\hline 1 & 2 & $20 \%$ \\
\hline TOTAL 5 & $\mathbf{3}$ & $\mathbf{1 0 0 \%}$ \\
\hline
\end{tabular}

Fonte: Elaborado pelos autores.

Conforme dados da tabela 2 anterior, foi observado que $60 \%$ das empresas que compõem o setor Siderúrgico brasileiro não registraram perda por impairment nos exercícios de 2008 a 2014, isso porque após aplicação do teste de recuperabilidade nos ativos imobilizados, essas empresas constataram que seus ativos imobilizados não estavam registrados por um valor superior ao valor recuperável. E apenas $40 \%$ das empresas registraram perda por impairment, $20 \%$ com o registro da perda em 1 ano, e $20 \%$ registraram a perda em 2 anos. O que mostrou que a maior parte das empresas do setor Siderúrgico brasileiro listadas na BM\&FBovespa no período de 2008 a 2014, não constataram que seus ativos imobilizados estavam registrados por um valor superior ao valor recuperável, ratificando os achados da pesquisa de Bezerra, Gallon e Luca (2014).

Tabela 3: Nível de Frequência de Ocorrência de Perda por Impairment do Ativo Imobilizado

\begin{tabular}{c|c}
\hline NÚMERO DE OCORRÊNCIAS/ANO & NÍVEL DE FREQUÊNCIA \\
\hline Nenhum & $91,43 \%$ \\
\hline 1 & $2,86 \%$ \\
\hline 2 & $5,71 \%$ \\
\hline
\end{tabular}

GєCont, v.6, n. 1, Floriano-PI, Jan-Jun. 2019. 


\begin{tabular}{r|c}
\hline TOTAL & $100 \%$ \\
\hline
\end{tabular}

Fonte: Elaborado pelos autores.

Tendo por base os dados da tabela 3 anterior, verificou-se que das Cias que compõem o setor Siderúrgico brasileiro de 2008 a 2014, após 35 possibilidades de ocorrência de perda por impairment, do total de ocorrências de perda no tocante a quantidade de anos, verificou-se que em $91,43 \%$ dos anos investigados, as empresas não constataram que seus ativos imobilizados estavam registrados por um valor superior ao valor recuperável. Enquanto, houve apenas uma ocorrência de perda registrada no ano de (2014), que corresponde a 2,86\%, e duas ocorrências de perdas no ano de (2009), que corresponde a 5,71\%. Evidenciou-se dessa forma, que das empresas do setor Siderúrgico brasileiro listadas na BM\&FBovespa no período de 2008 a 2014, no tocante ao número de registros de perda por impairment proporcional ao número de exercícios financeiros, não houve constatação que os ativos imobilizados estavam registrados por um valor superior ao valor recuperável na maioria dos anos $(91,43 \%)$, o que corrobora com as evidências da pesquisa de Bianchi et al. (2015), que das empresas da amostra, uma pequena parcela delas reconheceram a perda por desvalorização do ativo.

\section{CONCLUSÃO}

O objetivo deste artigo foi descrever a frequência que as empresas do setor Siderúrgico brasileiro listadas na BM\&FBovespa constataram que seus ativos imobilizados estão registrados por um valor superior ao seu valor recuperável no período de 2008 a 2014. Para isso, foram analisados os seguintes relatórios contábeis: Balanço Patrimonial (BP), Demonstração do Resultado do Exercício (DRE), Notas Explicativas (NE's) e Relatórios da Administração (RA's) dos exercícios compreendidos entre 2008 a 2014 de todas as empresas que compõem tal setor.

No tocante a frequência com que cada uma das empresas que compõem o setor Siderúrgico brasileiro constataram que seus ativos imobilizados estão registrados por um valor superior ao seu valor recuperável, verificou-se o seguinte: $60 \%$ dessas empresas após a aplicação do teste de recuperabilidade nos ativos imobilizados, constataram que seus ativos imobilizados não estavam registrados por um valor superior ao valor recuperável, por isso não registram perda por impairment de ativo imobilizado. E apenas $40 \%$ das empresas registraram perda por impairment, sendo $20 \%$ com o registro da perda em 1 ano, e $20 \%$ registraram a perda em 2 anos (dentro do intervalo dos exercícios compreendidos entre 2008 a 2014). Das cinco empresas que compõem o setor Siderúrgico brasileiro de 2008 a 2014, três delas não registram perda por impairment de ativo imobilizado em nenhum dos anos, e das duas que houve registros, uma empresa a ocorrência de perda por impairment foi registrada em apenas um ano, e outra empresa registrou as perdas em dois anos.

No que se refere a frequência de ocorrência de perdas por impairment de ativo imobilizado proporcional a quantidade de empresas que compõem o setor Siderúrgico brasileiro e a quantidade de registros de perdas por ano, constatou-se o que segue: em 91,43\% dos anos investigados, as empresas não constataram que seus ativos imobilizados estavam registrados por um valor superior ao valor recuperável. Enquanto, houve apenas uma ocorrência de perda registrada no ano de (2014), que corresponde a 2,86\%, e duas ocorrências de perdas no ano de (2009), que corresponde a 5,71\%. Portanto, dos 7 anos analisados das 5 empresas que compõem o setor Siderúrgico brasileiro, totalizando 35 possibilidades de 
ocorrência de perda por impairment no ativo imobilizado, ocorreram apenas 3 registros de perda por impairment do ativo imobilizado das empresas desse setor.

Verificou-se que todas as empresas deste setor aplicaram o impairment test em seus ativos imobilizados, mas a maioria delas não registraram perda por impairment no ativo imobilizado, nesse sentido, levantam-se os seguintes questionamentos: o teste de recuperabilidade de ativos realmente foram aplicados, conforme descrito nas Notas Explicativas analisadas; se os mesmos realmente foram aplicados, a aplicação foi feita adequadamente e periodicamente conforme determina o CPC 01 (2010). Não obstante, vale ressaltar que o fato de haver aplicação e na maioria dos casos não constatar-se que o valor contábil dos ativos imobilizados é superior ao valor recuperável, tais evidências não são conclusivas para determinar se houve ou não aplicação ou quanto a adequação do impairment test, contudo, tais questionamentos são válidos e relevantes para que a análise crítica prevaleça, para que outras pesquisas sejam realizadas pela comunidade científica, a fim de ampliar os estudos na área contábil. Outro questionamento sobre as evidências encontradas por este artigo, é feita com base no elevado número de anos que não houve registro de perda por impairment no ativo imobilizado após a aplicação do teste de recuperabilidade. Quando uma empresa ao aplicar o teste de recuperabilidade em seus ativos verifica nos primeiros anos que não houve perda por impairment, será que a aplicação do teste nos anos seguintes fica enviesada pelos resultados obtidos nos anos anteriores? Analogamente, aplica-se tal questionamento quando nos primeiros anos de aplicação do teste verifica-se que houve perda por impairment.

Essas foram algumas inferências levantadas por meio das evidências encontradas por este artigo sobre o nível de frequência de ocorrência de perda por impairment no ativo imobilizado das empresas do setor Siderúrgico brasileiro, outros questionamentos poderão ser levantados por outros pesquisadores e profissionais da área contábil. Entende-se que este artigo contribuiu para a ampliação do fenômeno estudado, por ter levantado evidências sobre o panorama da ocorrência de perda por impairment no ativo imobilizado das empresas do setor Siderúrgico brasileiro, informações que podem ser utilizadas tanto para saber a proporção de ocorrência e não ocorrência de registra de perda por impairment, bem como diversas outras inferências que poderão ser realizadas por meio da análise das evidências levantadas por este artigo.

Este artigo teve como limitação ter utilizado uma amostra pequena, composta por 5 empresas, entretanto, tal limitação, possibilitou realizar análise geral e individual das empresas que compõem o setor Siderúrgico brasileiro, esta que não seria possível se tratando de uma amostra grande.

Recomenda-se que outras pesquisas sejam produzidas semelhantes a esta ampliando o tamanho da amostra e a amplitude temporal, e também fazendo comparações entre os resultados encontrados entre os diferentes setores analisados.

\section{REFERÊNCIAS}

ABUADDOUS, M.; HANEFAH, M. M.; LAILI, N. H. Accounting standards, goodwill impairment and earnings management in Malaysia. International Journal of Economics and Finance, v. 6, n. 12, p. 201-211, 2014. 
AHMED, K.; ALAM, M. The Effect of IFRS Adoption on the Financial Reports of Local Government Entities. Australasian Accounting, Business and Finance Journal, v. 6, n. 3, p. 109-120, 2012.

AMARO, H. D.; BACHMANN, R. K. B.; FONSECA, M. W.; ESPEJO, M. M. S. B. Impairment e alisamento de resultados em companhias abertas do setor de energia elétrica do Brasil. Revista Mineira de Contabilidade, Belo Horizonte, v. 16, n. 1, p. 18-26, jan./abr. 2015.

BAKER, C. R.; WEARING, R. T. Impairment tests for goodwill instead of amortization: the potential impact on British companies. P. 1-22, 2001.

BEZERRA, C. S.; GALLON, A. V.; LUCA, M. M. M de. Redução ao valor recuperável de ativos e sua adoção nas empresas do setor de utilidade pública listadas na bm\&fbovespa à luz do CPC 01. Revista de Contabilidade e Controladoria, Curitiba, v. 6, n. 1, p. 8-27, jan./abr. 2014.

BIANCHI, C. R. C. D.; MONTI, M. P.; REINA, D.; REINA, D. R. M.; HEHR, D. A. Evidenciação do impairment test: análise das empresas pertencentes ao índice IBrX-100. Revista Mineira de Contabilidade, Belo Horizonte, v. 16, n. 1, p. 27-38, jan./abr. 2015.

BORINELLI, M. L.; PIMENTEL, R. C. Curso de Contabilidade para Gestores, Analista e outros Profissionais. São Paulo: Atlas, 2010.

BOWEN, R. M.; KHAN, U. Market reactions to policy deliberations on fair value accounting and impairment rules during the financial crisis of 2008-2009. Journal of Accounting and Public Policy, v. 33, p. 233-259, 2014.

BRASIL. Lei n ${ }^{\circ}$ 6.404, de 15 de dezembro de 1976. Dispõe sobre as Sociedades por Ações. Diário Oficial [da] República Federativa do Brasil, Brasília, 17 dez. 1976.

Lei $\mathrm{n}^{\circ} 11.638$, de 28 de dezembro de 2007. Altera e revoga dispositivos da Lei $\mathrm{n}^{\circ}$ 6.404, de 15 de dezembro de 1976, e da Lei $\mathrm{n}^{\circ}$ 6.385, de 7 de dezembro de 1976, e estende às sociedades de grande porte disposições relativas à elaboração e divulgação de demonstrações financeiras. Diário Oficial [da] República Federativa do Brasil, Brasília, 28 dez. 2007.

Lei $n^{\circ} 11.941$ de 27 de maio de 2009. Altera a legislação tributária federal relativa ao parcelamento ordinário de débitos tributários; concede remissão nos casos em que especifica; institui regime tributário de transição.

Lei $n^{\circ} 12.973$, de 13 de dezembro de 2014. Dispõe sobre alterações na legislação tributária federal relativa ao Imposto sobre a Renda das Pessoas Jurídicas - IRPJ, à Contribuição Social sobre o Lucro Líquido - CSLL, à Contribuição para o PIS/Pasep e à Contribuição para o Financiamento da Seguridade Social - Cofins e dá outras providências. Congresso Nacional [da] República Federativa do Brasil, Brasília, 13 de mai. de 2014.

CARLIN, T. M.; FINCH, N. Goodwill impairment testing under IFRS: a false impossible shore? Pacific Accounting Review, v. 23 n. 2, p. 368-392, 2011.

COELHO, C. U. F.; LINS, L. dos S. Teoria da Contabilidade: Abordagem Contextual, Histórica e Gerencial. São Paulo: Atlas, 2010.

CHEN, S.; WANG, Y.; ZHAO, Z. Evidence of asset impairment reversals from China: economic reality or earnings management? Journal of Accounting, Auditing and Finance, p. 1-44, 2008.

GєCont, v.6, n. 1, Floriano-PI, Jan-Jun. 2019. 
CPC, Comitê de Pronunciamentos Contábeis. Pronunciamento Técnico CPC no 01 Redução no Valor Recuperável de Ativos, de 06 de agosto de 2010.

DAMASCENO, F. S.; FUNCHAL, B. Valuing the impairment reverse loss effect on firm's debt financing. In: CONGRESSO DA ASSOCIAÇÃO NACIONAL DOS PROGRAMAS DE PÓS-GRADUAÇÃO EM CIÊNCIAS CONTÁBEIS, 9., 2015, Curitiba-PR. Anais... São Paulo: ANPCONT, 2015.

DEVALLE, A.; RIZZATO, F. The quality of mandatory disclosure: the impairment of goodwill. An empirical analysis of european listed companies. Procedia Economics and Finance, v. 2, p. 101-108, 2012.

INTERNACIONAL ACCOUNTING STANDARDS BOARD (IASB). IAS 36 - Impairment of Assets. Emitido em: mar. 2004.

LEMES, S.; CARVALHO. L. N. Contabilidade Internacional para Graduação: Texto, estudos de casos e questões de múltipla escolha. São Paulo: Atlas, 2010. 2010. Contabilidade internacional. Aplicação das IFRS 2005. 1 ed. São Paulo: Atlas,

MACHADO, E. A.; CRUZ, A. P. C.; TAKAMATSU, R. T.; LIMA, G. A. S. F. Evidências de disclosure de valor recuperável de ativos em firmas listadas no mercado acionário brasileiro. Revista Universo Contábil, Blumenau, v. 9, n. 1, p. 86-103, jan./mar. 2013.

MACHADO, L. de S.; MACHADO, M. R. R.; FLORESTA, M. S. Evidenciação e divulgação das práticas contábeis aplicadas aos ativos imobilizados e intangíveis, por entidades localizadas em goiás, sob a ótica das IFRS. Revista de Contabilidade da UFBA, Salvador, v. 7, n. 3, p. 23-37, dez./mar. 2014.

MARION, J. C.; DIAS, R.; TRALDI, M. C. Monografia para os cursos de administração, contabilidade e economia. São Paulo: Atlas, 2002.

MARQUES, M. da C. da C. Impairment of assets appraised in accordance with IAS 36. American Based Research Journal, v. 2, p. 23-34, 2013.

MARTINS, G. de A.; THEÓPHILO, C. R. Metodologia da investigação científica para ciências sociais aplicadas. São Paulo: Atlas, 2007.

MAZZIONI, S.; POLITELO, L.; MOREIRA, W. J.; KLAN, R. C. Fatores determinantes na evidenciação da redução ao valor recuperável de ativos (impairment test) em empresas listadas na bm\&fbovespa. Revista de Administração e Contabilidade da Unisinos, Rio Grande do Sul, v. 11, n. 4, p. 276-291, out./dez. 2014.

NASCIMENTO, J. O.; PARIS, C.; WEFFORT, E. F. J.; PETERS, M. R. S. Aspectos contábeis do tratado de itaipu: análise das práticas de mensuração, depreciação, manutenção e impairment dos ativos imobilizados da empresa itaipu binacional. Revista de Informação Contábil, Recife, v. 7, n. 4, p. 01-19, out./dez. 2013.

ONO, H. M.; RODRIGUES, J. M.; NIYAMA, J. K. Disclosure sobre impairment: uma análise comparativa das companhias abertas brasileiras em 2008. Revista de Contabilidade do Mestrado em Ciências Contábeis da UERJ, Rio de Janeiro, v. 15, n. 1, p. 67-87, jan./abr. 2010.

GєCont, v.6, n. 1, Floriano-PI, Jan-Jun. 2019. 
PACHARN, P.; ZHANG, L. Accounting, innovation and incentives. Journal of Engineering and Technology Management, v. 23, p. 114-129, 2006.

RAUPP, F. M.; BEUREN, I. M. Contribuição ao processo de mensuração de ativos imobilizados por meio do fair value e do impairment test. Revista de Informação Contábil, Recife, v. 3, n. 2, p. 1-16, abr./jun. 2009.

REIS, A. de O.; ANJOS, D. A.; SEDIYAMA, G. A. S.; LÉLIS, D. L. M. Disclosure da recuperabilidade do valor do ativo imobilizado: análise no setor siderúrgico brasileiro. Revista Ambiente Contábil, Natal, v. 5, n. 2, p. 37-52, jul./dez. 2013.

ROMANO, M. Accounting for impairment test of investments in subsidiaries and associates. Journal of American Academy of Business, v. 12, n. 2, p. 167-173, 2008.

SANTOS, E. S. Análise dos impactos dos CPCs da primeira fase de transição para o IFRS no Brasil: um exame dos ajustes aos resultados nas DFPS de 2008. Revista de Contabilidade e Organizações, Ribeirão Preto, v. 6, n. 15, p. 24-43, mai./ago. 2012.

SOUZA, M. M. de; BORBA, J. A.; ZANDONAI, F. Evidenciação da perda no valor recuperável de ativos nas demonstrações contábeis: uma verificação nas empresas de capital aberto brasileiras. Revista Contabilidade Vista \& Revista, Belo Horizonte, v. 22, n. 2, p. 67 91, abr./jun. 2011.

TAVARES, M. F. N.; FILHO, J. F. R.; LOPES, J. E. G.; VASCONCELOS, M. T. C.; PEDERNEIRAS, M. M. M. Um estudo sobre o nível de conformidade dos setores classificados pela bovespa com o CPC 01 - redução ao valor recuperável de ativos. Revista Sociedade, Contabilidade e Gestão, Rio de Janeiro, v. 5, n. 1, p. 18-26, jan./jun. 2010.

TREWAVAS, K.; REDMAYNE, N. B.; LASWAD, F. The impact of IFRS adoption on public sector financial statements. Australian Accounting Review, v. 22, p. 86-102, 2012.

ULIANO, A. L.; GONÇALVES, M. N.; DONÁ, A. L. Disclusore da perda por impairment aplicado ao ativo imobilizado: análise nas companhias do IBrX-501. Revista Enfoque Reflexão Contábil, Fortaleza, v. 33, n. 1, p. 1-18, jan./abr. 2014.

VERGARA, S. C. Projetos e relatórios de pesquisa em administração. 6. ed. São Paulo: Atlas, 2005.

WATTS, R. L. Conservatism in accounting part I: explanations and implications. Accounting Horizons, v. 17, n. 3, p. 207-221, 2003.

GєCont, v.6, n. 1, Floriano-PI, Jan-Jun. 2019. 